\title{
In Vitro Propagation of Cucurma Aeruginosa Roxb in Liquid Culture
}

\author{
Alizah Z*, Nurulaishah Y, Adilah A
}

Biotechnology \& Nanotechnology Research Centre Malaysian Agriculture Research and Development Institute Serdang, PO Box 12301, Kuala Lumpur

\section{*Corresponding Author}

Alizah Z

\section{Article History}

Received: 11.11.2019

Accepted: 18.11 .2019

Published: 30.11 .2019

\begin{abstract}
Curcuma aeruginosa Roxb. $\mathrm{H}$ or Temu hitam is an important medicinal plant. This potential herb has been used in traditional medicine to treat various diseases. Due to its high medicinal value and absence of propagation system, tissue culture technique can be utilized to overcome this problem. In this study, multiple shoots formation was induced from young bud of $C$. aeruginosa Roxb. Cultured in MS liquid medium containing various concentration of 6-benzylaminopurine (BAP). Shoots were induced in MS liquid medium supplemented with BAP after 8 weeks of culture. Optimum shoots induction occurred at $4 \mathrm{mg} / \mathrm{L}$ BA with an average of 18 shoots per explant. The plantlets grew well without any phenotypic aberrations. They were transferred to MSO prior to acclitimazation. This protocol could be useful for germplasm conservation and cultivation of $C$. aeruginosa.
\end{abstract}

Keywords: Curcuma aeruginosa, liquid culture, shoot multiplication, in vitro propagation.

\section{INTRODUCTION}

Curcuma aeruginosa Roxb. $\mathrm{H}$ has been used in traditional medicinal to treat various ailments. Extensive research within the last half century has proven that this plant had been shown to exhibit antioxidant, anti-inflammatory, antiviral, antibacterial, antifungal, and anticancer activities and thus has a potential against various malignant diseases, diabetes, allergies, arthritis, Alzheimer's disease, and other chronic illnesses [1]. This plant can also be used for food preservation, pharmaceutical treatment and natural therapies [2]. This underexploited Curcuma species which could serve as a new source of important phytochemicals and natural antioxidant that could be incorporated in functional foods and nutraceuticals [3].

However, this important plant has not received the attention from tissue culture compared to other Curcuma species. Only few reports are available on the in vitro multiplication of this crop and the multiplication rate is very low (1-4 shoots/explant). Thus, the aim of this work was to develop an efficient protocol for $\mathrm{C}$. aeruginosa shoot multiplication production using liquid medium. This technique would facilitate and accelerate the plant multiplication for rapid large-scale clonal propagation. This method would also help to maintain the uniform and consistent production of true to-type plants within a short period of time

\section{Material and Methods}

Healthy sprouted buds from rhizome were cut and washed thoroughly with detergent and tap water. Cleaned buds were surface sterilized with $20 \%$ Clorox® for $15 \mathrm{~min}$, and rinsed three times with sterile distilled water. They were again surface sterilized with $5 \%$ Clorox® and rinsed again three times with sterile distilled water. The sterilized buds were cultured on MS medium [4] supplemented with $3 \mathrm{mg} / \mathrm{L} \mathrm{BAP}$ for 4 weeks. From these cultures, shoot measuring $0.5 \mathrm{~cm}$ were taken as an explant for subsequent experiments. Shoots were cultured into $250 \mathrm{ml}$ Erlenmeyer flask containing $100 \mathrm{ml}$ of MS [4] liquid medium supplemented with various concentration of 6-benzylaminopurine (BAP) $(1.0-6 \mathrm{mg} / \mathrm{L})$. The cultures were incubated on a rotary shaker at $100 \mathrm{rpm}$.

Shoots were collected after 8 weeks and the mean number of shoots per culture flask in liquid media was determined. The experiments were replicated three times, through three successive subcultures. Each treatment consisted of 5-10 flasks and each flask contained three explants. The values are recorded as means \pm standard error.

Copyright @ 2019: This is an open-access article distributed under the terms of the Creative Commons Attribution license which permits unrestricted use, distribution, and reproduction in any medium for non commercial use (NonCommercial, or CC-BY-NC) provided the original author and source are credited. 


\section{RESULTS \& DISCUSSION}

Shoots were cultured in MS liquid medium supplemented with 1-6 mg/L BAP to determine the best concentration for production of multiple shoots. Initially one shoot per explant emerged after 5 to 8 days of inoculation and gradually the number of shoots per explant increased depended on BAP concentration. After 8 weeks, results showed $100 \%$ of the explants produced shoots on induction medium. An average of 1 to 18 shoots was formed from each treatment. MS medium supplemented with 4 mg/L BAP produced the highest number of shoots, 18 shoots per explant (Fig. 1 \& 2). These results showed that BAP was effective in the induction of multiple shoot. The stimulating effect of BAP on multiple shoot formation has been reported earlier for eight wild species of Curcuma [5]. The number of shoots produced in liquid medium were increased as compared to shoots cultured on solid medium which only produced up to 4 shoots/explant [5,6]. Possibly, this is because the shoots are submerged in the liquid medium presenting a large surface area for the uptake of nutrients and growth regulators compared to agar-gelled medium. Liquid medium also provides rapid uptake of the nutrients by the cells and speedy nutrients replacement at the cell surface [7]. Improvement on the rate shoot multiplication in liquid media has also been reported for several other plant species, such as C. zedoaria and Zingiber zirumbet [8], Aloe vera [9], Picrorhiza kurroa [10]. Vyas et al. [12] suggested that in vitro propagation in liquid medium is more effective for some medicinal plants.

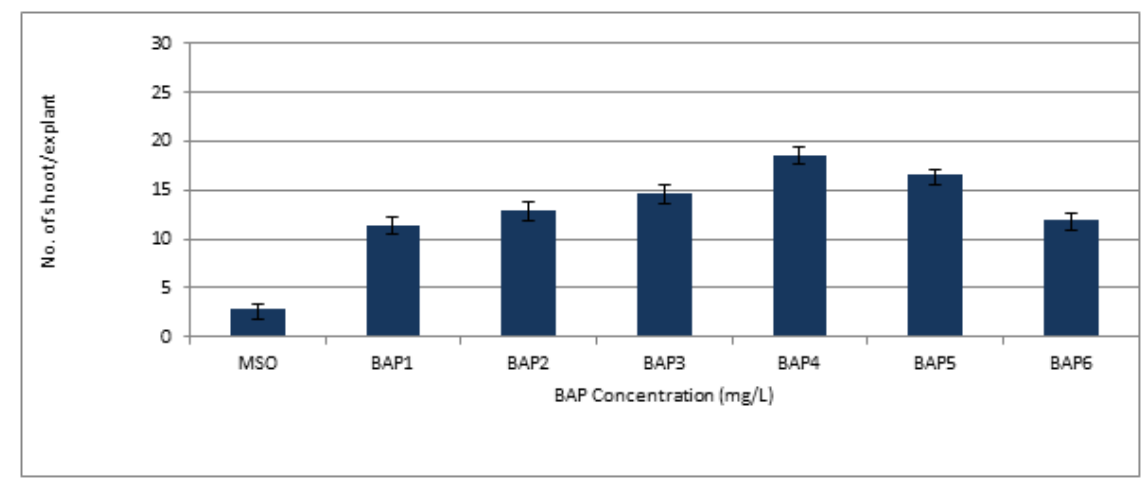

Fig-1: Effect of different concentration of BAP on shoot induction of $C$. aeruginosa
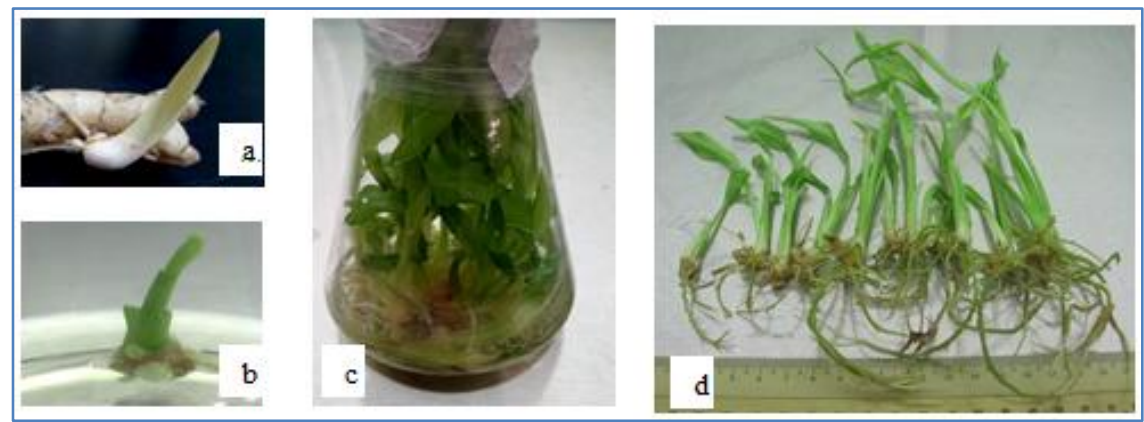

Fig-2: In vitro micropropagation of C. aeruginosa in liquid medium. (a) Healthy sprouted buds from rhizome (b) Sterilized nodal segment after 5 days on MS media without PGR. (c) Multiple shoots formation in MS liquid medium after 8 weeks of cultivation on MS medium supplemented with BAP (4mg/L). (d) Healthy plantlets ready to be acclimatized.

However, on lowering the concentration of BAP from their optimum concentration the number of shoots per explant was reduced. In general, the number of shoots per explant increased to a certain concentration and declined with the increase or decrease in concentration of cytokinin beyond their optimal level. Reduction in shoot number at concentrations higher or lower than optimal level has also been reported for several medicinal plants [13-15]. Higher concentrations of BAP not only reduced the number of shoots formed but also resulted in stunted growth of the shoots. No abnormality such as hyperhydricity and fascinated shoots was observed on shoots produced using liquid medium (Fig 2d). The regenerated shoots were washed thoroughly and placed in a mixture of sterilized vermiculite and sterilized soil (1:1) before acclimatized in greenhouse.

\section{CONCLUSION}

In this paper we report for the first time the micropropagation of $C$. aeruginosa grown in liquid culture. This system could be useful for increasing the scale of production and cost reduction. Optimum adventitious shoots induction occurred at $4 \mathrm{mg} / \mathrm{L}$ BA with an average of 18 shoot buds per explant. This protocol can be suitably exploited for mass multiplication on a large scale for commercial. 


\section{ACKNOWLEDGEMENT}

This project was supported by the Science Fund Grant (02-03-08-SF 0337) from Ministry of Science, Technology \& Innovation, Malaysia (MOSTI)

\section{REFERENCES}

1. Aggarwal, B. B., Sundaram, C., Malani, N., \& Ichikawa, H. (2007). Curcumin: the Indian solid gold. In The molecular targets and therapeutic uses of curcumin in health and disease (pp. 1-75). Springer, Boston, MA.

2. Kamazeri, T. S. A. T., Samah, O. A., Taher, M., Susanti, D., \& Qaralleh, H. (2012). Antimicrobial activity and essential oils of Curcuma aeruginosa, Curcuma mangga, and Zingiber cassumunar from Malaysia. Asian Pacific journal of tropical medicine, 5(3), 202-209.

3. Simoh, S., SHIN, S., RAHIM, F. A., \& ZAINAL, M. A. A. A. (2018). Comparative Analysis of Metabolites and Antioxidant Potentials from Different Plant Parts of Curcuma aeruginosa Roxb. Sains Malaysiana, 47(12), 3031-3041.

4. Murashige, T., \& Skoog, F. (1962). A revised medium for rapid growth and bio assays with tobacco tissue cultures. Physiologia plantarum, 15(3), 473-497.

5. Tyagi, R. K., Yusuf, A., Dua, P., \& Agrawal, A. (2004). In vitro plant regeneration and genotype conservation of eight wild species of Curcuma. Biologia Plantarum, 48(1), 129-132.

6. Alizah, Z., Nurulaishah, Y., Adilah, A., \& Mohd Hafiz, F. H. (2013). In vitro micropropagation of Temu Hitam. Plant physiology in addressing green economy, 139.

7. Theanphong, O. R. A. W. A. N., Songsak, T. H. A. N. A. P. A. T., \& Kirdmanee, C. H. A. L. E. R. M. P. O. L. (2010). Effect of plant growth regulators on micropropagation of Curcuma aeruginosa Roxb. Thai Journal of Botany, 2, 135-142.

8. Gupta, P. K., \& Timmis, R. (2005). Mass propagation of conifer trees in liquid cultures-progress towards commercialization. In Liquid Culture Systems for in vitro plant propagation (pp. 389-402). Springer, Dordrecht.

9. Stanly, C., \& Keng, C. L. (2007). Micropropagation of Curcuma zedoaria roscoe and Zingiber zerumbet smith. Biotechnology, 6(4), 555-560.

10. Singh, M., Rathore, M. S., Panwar, D., Rathore, J. S., Dagla, H. R., \& Shekhawat, N. S. (2009). Micropropagation of selected genotype of Aloe vera L.-an ancient plant for modern industry. Journal of Sustainable Forestry, 28(8), 935-950.

11. Chauhan, H. S. S. (2009). Development of a Low Cost Micro propagation Technology for an Endangered Medicinal Herb (Picrorhiza kurroa) of North-Western Himalayas.

12. Vyas, S., Rao, M. S., Suthar, R. K., \& Purohit, S. D. (2008). Liquid culture system stimulates in vitro growth and shoot multiplication in four medicinally important plants. Medicinal and Aromatic Plant Science and Biotechnology, 2(2), 96-100.

13. Haw, A. B., \& Keng, C. L. (2003). Micropropagation of Spilanthes acmella L., a bio-insecticide plant, through proliferation of multiple shoots. J. Appl. Hort, 5(2), 65-68.

14. Hiregoudar, L. V., Murthy, H. N., Bhat, J. G., Nayeem, A., Hema, B. P., Hahn, E. J., \& Paek, K. Y. (2006). Rapid clonal propagation of Vitex trifolia. Biologia Plantarum, 50(2), 291-294.

15. Alatar, A. A., Faisal, M., Hegazy, A. K., \& Hend, A. A. (2012). High frequency shoots regeneration and plant establishment of Rauvolfia serpentina: An endangered medicinal plant. Journal of Medicinal Plants Research, 6(17), 3324-3329. 